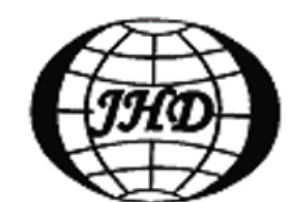

www.sciencedirect.com/ science/journal/10016058

\title{
OVERIVEW OF THE 6TH INTERNATIONAL CONFERENCE ON ASIAN AND PACIFIC COASTS
}

\author{
LU Dong-qiang \\ Shanghai Institute of Applied Mathematics and Mechanics, Shanghai University, Shanghai 200072, China, \\ E-mail:dqlu@shu.edu.cn
}

The 6th International Conference on Asian and Pacific Coasts (APAC2011) was held in Hong Kong during December 14-16, 2011. This conference was jointly supported by the Chinese Ocean Engineering Society, the Coastal Engineering Committee of Japan Society of Civil Engineers, and the Korean Society of Coastal and Ocean Engineers, and was organized by Departments of Civil and Mechanical Engineering, The University of Hong Kong ${ }^{[1]}$. More than 320 delegates from over 30 countries/regions, including China, Japan, Korea, Australia, Belgium, Demark, France, India, Indonesia, Italy, Netherlands, Russia, Singapore, UK, USA etc., attended the conference.

The conference technical presentation consisted of six 40-minute keynote lectures, four 30-miniute invited lectures, 10 contributions to the Special Session on the 2011 East Japan Tsunami, and 237 other papers in 46 oral sessions and in 2 poster sessions. The speakers and titles of the six keynotes are listed as follows:

(1) Harindra J.S. Fernando (Univ. Notre Dame, USA): Toward sustainable and secure coastal zones: roles of waves, tides, sediments, and turbulence,

(2) Hajime Mase (Kyoto Univ., Japan): Climate change effects on future waves and typhoons,

(3) Peidong Lu (NHRI, China): Hydrodynamics research and application of the radial sand ridge in South Yellow Sea, China,

(4) Kyung-Duck Suh (Seoul National Univ., Korea): Performance-based design of caisson breakwater incorporating wave height increase due to climate change,

(5) Cameron M. Johnstone (Nautricity Ltd., UK): The challenges to be addressed if tidal energy is to become economically viable,

(6) Harry Yeh (Oregon State Univ., USA): Tsunami amplification and breaking along a vertical wall.

The conference proceedings (CD-ROM), edited by Joseph Hun-Wei Lee and Chiu-On Ng and publi- shed by the World Scientific with the ISBN 978-9814366-47-2, cover a wide range of topics related to coastal, ocean and harbor engineering, such as "beach erosion and morphodynamics, climate change and sea level rise, coastal management and shore protection, estuaries and ports, hydrodynamics of offshore and coastal structures, marine ecology and environment, marine and offshore wind energy, seawater intrusion, sediment transport, tsunami and storm surges, waves and tides, wastewater disposal and water quality, and so on" $"[2,3]$.

The conference was first held in Dalian, China in 2001 by the name of Asian and Pacific Coastal Engineering (APACE) and was renamed to Asian and Pacific Coasts (APAC) to reflect a broader scope. The APAC series had been successively held in Chiba, Japan (2004), Jeju, Korea (2005), Nanjing, China (2007), and Singapore (2009). According to the APAC2011 announcement, the purpose of this APAC conference is "to promote scientific advancement, technological progress, information exchange, and cooperation among engineers and researchers in coastal, port, and ocean engineering and other related fields, $[1]$.

The 7th International Conference on Asian and Pacific Coasts (APAC2013) will be held in Bali, Indonesia on September 24-26, 2013, and be hosted by the Hasanuddin University, Indonesia.

\section{References}

[1] http://www.apac2011.org

[2] LEE Joseph Hun-Wei and NG Chiu-On (Eds.) Asian and Pacific Coasts 2011-Proceedings of the 6th International Conference on Asian and Pacific Coasts, World Scientific, 2011.

[3] http://eproceedings.worldscinet.com/9789814366489/ 9789814366489.shtml 